\title{
Administración comunitaria del reciclamiento de desechos: El SIRDO
}

Marianne Schmink

Follow this and additional works at: https://knowledgecommons.popcouncil.org/departments_sbsr-pgy

Part of the Community-Based Learning Commons, Family, Life Course, and Society Commons, International Public Health Commons, Place and Environment Commons, and the Urban Studies and Planning Commons How does access to this work benefit you? Let us know!

\section{Recommended Citation}

Schmink, Marianne. 1984. "Administración comunitaria del reciclamiento de desechos: El SIRDO," SEEDS no. 8. New York: Population Council. 
SEEDS (Semillas) es el nombre de una serie de folletos diseñados con el objeto de responder a las solicitudes recibidas de todo el mundo en las que se pide información sobre ideas de programas prácticos e innovadores en beneficio de mujeres de ingresos bajos, sugeridas por ellas mismas o por otras personas. Los folletos sirven como medio de compartir tal información y de incitar el establecimiento de nuevos proyectos basados en las experiencias positivas de mujeres que trabajan, no solo para ayudarse a sí mismas, sino también a otras mujeres, a mejorar su situación económica. Los proyectos que se describen en esta edición de SEEDS, así como los que se incluirán en futuras ediciones, se seleccionan por varias razones: producen dinero en efectivo para las mujeres; las hacen participar en el proceso de la toma de decisiones, especialmente aquéllas que les permiten escoger la forma en que van a percibir sus propios ingresos; se basan en sólidos criterios económicos y han logrado superar con éxito los obstáculos que se encuentran con major frequencia. Estos informes no tienen carácter de preceptos, ya que cada esfuerzo en pro del desarrollo, tiene que entendérselas con problemas y recursos diferentes. Lo que tratan de hacer es describir la historia de una idea y de su realización, en la esperanza de que las lecciones que se aprendan con ella puedan ser útiles en otros lugares y situaciones. También se escriben estos informes para llamar la atención de aquéllos que ocupan posiciones altas, donde se toman las decisiones, sobre el hecho de que proyectos generadores de ingresos para las mujeres o realizados por ellas, son viables y tienen una función muy importante que desempeñar en la esfera del desarrollo.

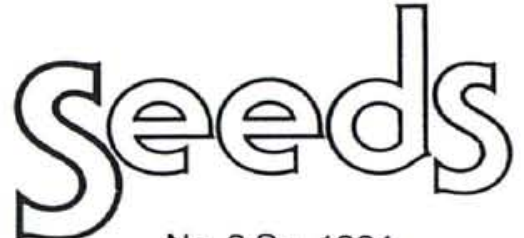

No. 8 Sp. 1984
SEEDS recibe apoyo administrativo del Population Council. Su política editorial la determina el Comite Directivo de SEEDS, compuesto por las siguientes personas: Kristin Anderson (Center for Public Advocacy Research), Judith Bruce (The Population Council), Katherine McKee (The Ford Foundation), Jill Sheffield (The Carnegie Corporation) y Ann Leonard (Editora).
La traducción de esta edicion de SEEDS al español fue subvencionada por: Women in Development Office Agency for International Development Washington. D.C. 20523 U.S.A. 


\title{
Administración Comunitaria del Reciclamiento de Desechos: EI SIRDO
}

\author{
Historia de Marianne Schmink
}

\section{Introducción}

A comienzos de 1978, un grupo de familias esperaba que le adjudicaran una de las casas comprendidas en un proyecto de viviendas económicas en Mérida, una ciudad de la costa sudeste de México. Por lo general, estas casas de bajo costo solo tienen tres habitaciones provistas de servicios de agua, electricidad y desagüe. La lista de espera para casas dotadas con el sistema típico de desagüe usado en la región-un pozo de absorbimiento y un tanque séptico-era muy larga. Habia, sin embargo, otras casas que contaban con un sistema de drenaje nuevo Ilamado SIRDO (Sistema Integrado de Reciclamiento de Desechos Orgánicos). Costaba 20 por ciento menos que el sistema convencional y disminuia los riesgos de la contaminación ambiental. Además, las familias interesadas en vivir en la manzana experimental donde se instalaría el SIRDO, podrian ocupar su casa inmediatamente. Las que aceptaron esta oferta, se vieron obligadas a hacerlo, por la urgente necesidad que tenian de encontrar dónde vivir. A pesar de que se les explicó en qué consistía el SIRDO, en su gran mayoria se pasaron a vivir a la casa sin entenderlo bien todavia. Tampoco tenian forma de darse cuenta de que estaban a punto de convertirse en los pioneros de la adopción y diseminación de una nueva tecnologia.

Tres años más tarde, otro grupo de familias de una comunidad situada en el populoso Valle de México, buscaba la solución a un creciente problema de eliminación de desechos. Después de enterarse de la existencia del SIRDO, y de hacer una visita al proyecto experimental de Mérida, las familias resolvieron ensayarlo en su propio vecindario. A pesar de las diferencias que existen entre ellos, los dos grupos han afrontado problemas similares en el proceso de aprender a manejar los aspectos técnicos, económicos y sociales de una tecnología nueva de tipo comunitario. Las mujeres han desempeñado un papel esencial en este proceso, reforzando con ello la posición que ocupan dentro de sus familias y de la colectividad. Han llegado a ser además las principales encargadas del manejo de un sistema que, aparte de mejorar las condiciones sanitarias, ofrece la posibilidad de realizar actividades comunitarias productoras de ingresos. Lo que sigue a continuación es la historia de estas señoras, de las comunidades en que viven y de los cambios ocasionados por esta nueva tecnología. 


\section{El Sitio: Mérida}

La cuidad de Mérida, en el extremo noroeste del estado de Yucatán, en la península del mismo nombre, dista poco de Centroamérica. Por muchos siglos, antes de la conquista española, los mayas ocuparon la península de Yucatán, el estado Chiapas y las tierras altas guatemaltecas. En toda esta zona aún existen rastros de la herencia que dejaron. Por allá en 1600, Mérida, que había sido conquistada por los españoles en 1542, era el centro político, económico y cultural de la región. Entre el período colonial y la primera guerra mundial, creció en tamaño e importancia gracias al sistema agricola tradicional de las haciendas que florecieron en sus alrededores. De mediados del siglo diecinueve a comienzos del siglo veinte, durante el auge de la producción del henequén (fibra parecida al sisal con la que se hacen cuerdas, cordeles, tapetes, etc.), Yucatán fue el estado más rico de México. Casas palaciegas bordeaban el bulevar principal de Mérida. Sin embargo, solo un pequeño grupo adinerado controlaba esta riqueza; el resto de la población lo formaban campesinos que escasamente subsistian y peones contratados por las haciendas. A principios del decenio de 1930, la producción del henequén comenzó a decaer y la región entró en un largo período de depresión, que resultó en una dependencia cada vez mayor de los programas del gobierno.

Hoy en día, la ciudad depende todavía de lo que producen los campesinos de los alrededores, pero la economía urbana tiene como base el comercio, el turismo y otros servicios. El sector industrial predominante lo forman empresas pequeñas, legado de los talleres artesanales que se crearon para servir la industria del henequén. Hoy, éste es aún el renglón industrial más grande, pero continúa decayendo. La actividad manufacturera se concentra en mercancias de consumo como alimentos, bebidas y ropa. Con una base económica débil y la migración continua que recibe del campo, la ciudad afronta un creciente problema de desempleo. Su población, de unos 400.000 habitantes, representa aproximadamente la tercera parte de la población total del estado, pero dicha proporción sigue en aumento. Gran número de estos inmigran- tes se establecen en las zonas más pobres, al sur de la ciudad. Es alli donde se adelanta el proyecto de viviendas económicas conectadas al SIRDO, el nuevo sistema de desagüe.

\section{¿Qué es el SIRDO?}

Desde 1978, el Grupo de Tecnología Alternativa (GTA), de Mérida, ha venido desarrollando el SIRDO. EI GTA es un grupo pequeño fundado por la arquitecta Josefina Mena, y dedicado a la búsqueda de una tecnologia para el reciclado de desechos orgánicos en las zonas urbanas. EI SIRDO no se diseñó únicamente para eliminar basuras y desperdicios, sino como un proceso potencial de actividades laborales productoras de ingresos. Es un sistema que requiere gran cantidad de mano de obra en todas sus etapas, desde construcción, hasta mantenimiento y producción. Sus características hacen posible el manejo cooperativo comunitario de su funcionamiento diario.

Básicamente el SIRDO funciona de la siguiente manera: cada casa se conecta con el sistema comunitario con dos tubos separados: uno para las "aguas grises"

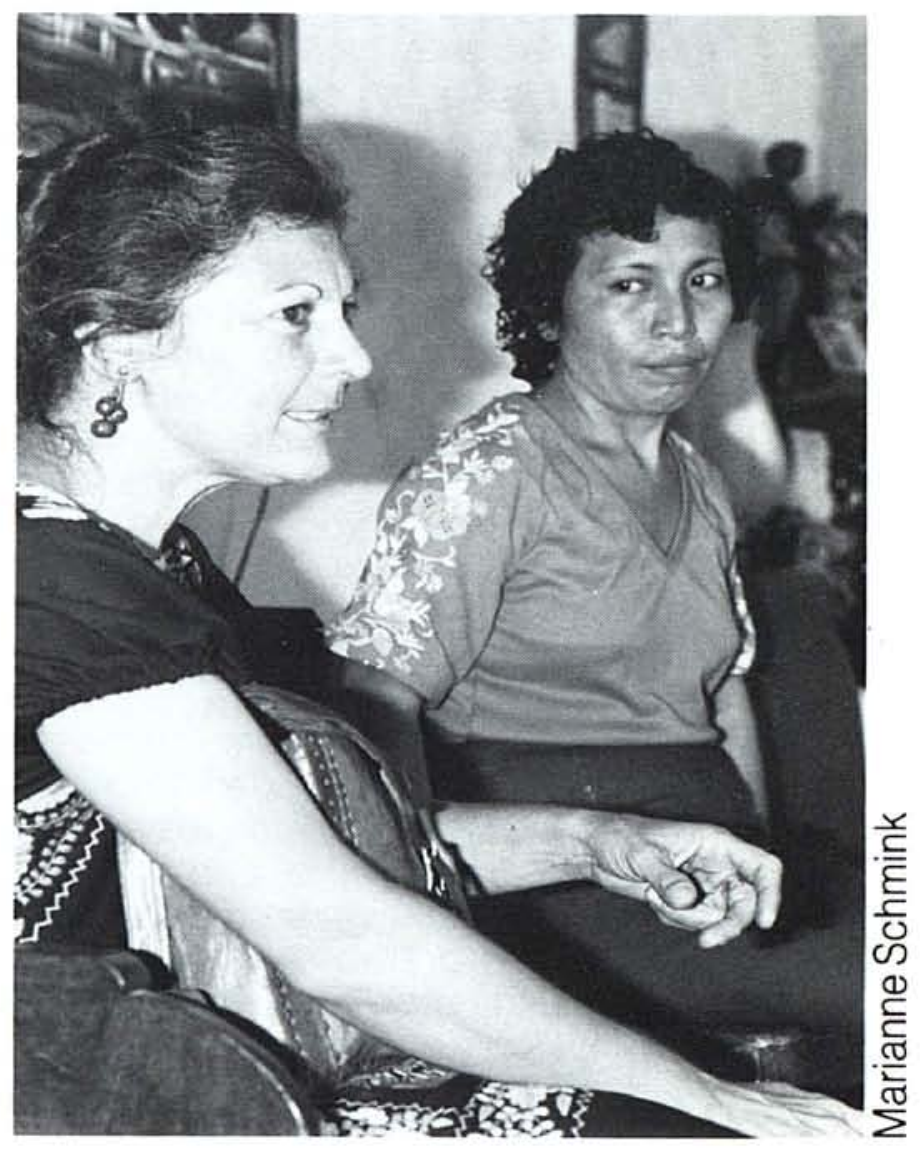




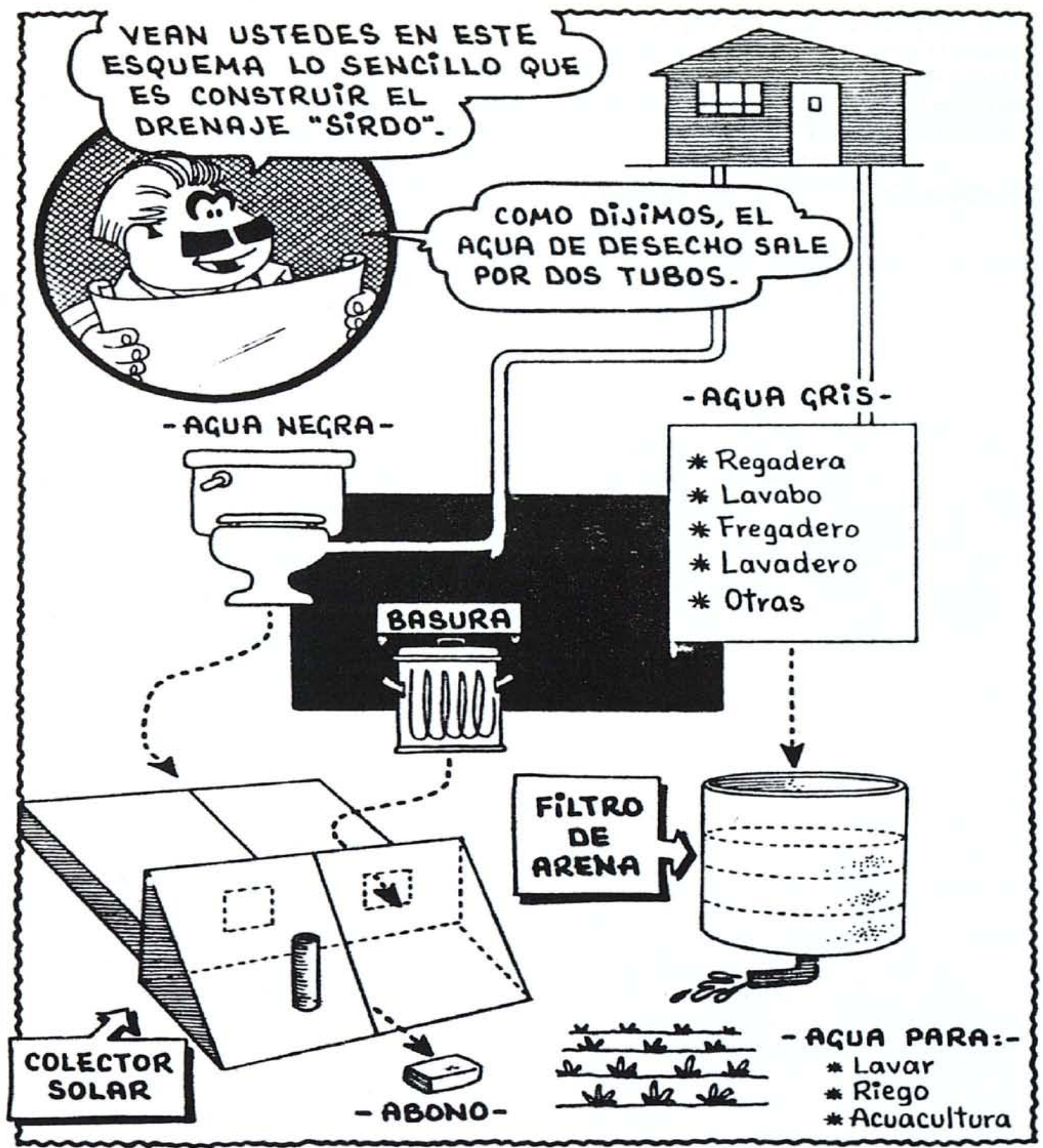

6.

(provenientes del baño, la cocina y el lavado de la ropa, que contienen detergentes), y las "aguas negras" que salen del inodoro. Después de filtradas, el ochenta por ciento de las "aguas grises", pueden utilizarse de nuevo como agua de riego. Las "aguas negras" van a un tanque, donde el cieno se separa del agua. El cieno se extiende en una cámara aeróbica de descomposición y se mezcla luego con la basura de la casa. Alli el agua se evapora mediante un proceso de secamiento solar y en el término de un año, lo que resta se

convierte en un fertilizante rico en sustancias nutritivas. Entre tanto, las "aguas negras", adecuadamente tratadas, van a dar a los surcos de las huertas donde crecen flores y vegetales. También se las canaliza hacia estanques destinados a la cría de peces.

El SIRDO es un sistema único, por requerir un cuidadoso control de las varias etapas del proceso de descomposición. algo imposible de realizar en un sistema municipal a grande escala. Por otro lado, es demasiado costoso para instalarse indivi- 
dualmente en cada casa. De ahi que resulte ideal para un manejo de tipo comunitario. El GTA adapta la instalación del SIRDO a cada sitio especial y continúa vigilándolo para asegurar su buen funcionamiento.

\section{Instalación del SIRDO en Mérida}

Entre enero y mayo de 1980, GTA construyó los dos primeros SIRDOS en Mérida. Fueron financiados por una dependencia del gobierno encargada de facilitarle a la gente pobre la adquisición de lotes para viviendas provistas de servicios básicos. La oficina central de la dependencia en cuestión, se interesó en la nueva tecnología, y su oficina regional de Mérida, con alguna renuencia, se vio forzada a modificar su programa de vivienda, a fin de permitir la instalación del nuevo sistema de eliminación de desechos. Además de ofrecer lotes con agua y electricidad, la oficina regional pagó la instalación del SIRDO y lo conectó con las viviendas básicas de tres habitaciones (a las que las familias pueden añadir otras más tarde). De acuerdo con los planes originales, las casas y los desagües se instalarian en veintiocho manzanas, cerca del extremo sur de la ciudad. Al final, sin embargo, solo una se dotó con el SIRDO.

A finales de 1980, la oficina regional le adjudicó a veinticuatro familias las casas del bloque experimental. Poco a poco comenzaron a ocuparlas. En casi todas ellas, los hombres trabajaban en servicios, negocios pequeños o eran artesanos. La mayoría trabajaba por cuenta propia y los ingresos de más de la mitad de ellos eran inferiores al salario mínimo de aquel entonces. Casi ninguna mujer tenía empleo regular, pero como las uniones matrimoniales no son siempre estables, muchas habian trabajado en algún momento de su vida, para proveer sustento primario o complementario a la familia. Las que tenían empleo lo hacian generalmente como sirvientas, o en expendios pequeños de víveres o de otros artículos. Solo una mujer trabajaba en una fábrica. En promedio, las familias tenían tres hijos y la mayoría de los adultos sabian leer y escribir, pero no habian pasado de la escuela primaria. En agosto de 1979, el GTA celebró una serie de charlas de orientación sobre el SIRDO a las que las familias asistieron con cierto escepticismo. El sistema comenzó a funcionar, pero fueron muchos los problemas que se presentaron en un principio. Los usuarios se quejaron de que había moscas, mal olor y escapes de líquidos. Además, fue necesario hacer cambios en la rutina de la casa. No podían usarse productos ácidos porque alteraban la composición química de la cámara de descomposición. También se requería separar la basura orgánica de las materias plásticas, de vidrio o de metal, que no podían echarse en la cámara. Por estas razones, algunos de los miembros de la comunidad se opusieron al sistema, a pesar de las aseveraciones del GTA respecto a las ventajas que ofrecía. Pronto, sin embargo, los malos olores comenzaron a desaparecer, y los demás problemas se solucionaron. Es interesante señalar que, desde un principio, los nin̄os colaboraron con el personal del GTA, participando en tareas de mantenimiento, como la separación de la basura y el depósito de los desperidicios orgánicos dentro de la cámara. Llegaron inclusive a pintar murales que mostraban cómo usar el sistema. Como resultado del entusiasmo de los niños, muchas de las mujeres empezaron a cooperar también. En mayo de 1981, comenzaron a reunirse para adjudicar las tareas con base en la cooperación comunitaria. Formaron además un comité encargado de proteger el SIRDO contra el vandalismo de quienes se oponían a él.

Una oposición muy fuerte se hizo sentir en los dos sitios donde el nuevo sistema se instaló inicialmente. En México, como en otros países, la política influye en la adjudicación de terrenos y servicios urbanos. Lo típico es que individuos o grupos dirigentes de la comunidad reconozcan la necesidad que existe de ciertos servicios o de sitios para viviendas, y organicen a los residentes para que presenten peticiones a los políticos del partido de gobierno. Los organismos oficiales, a su turno, tratan de establecer con dichos líderes una relación similar a la que existe entre "patrones y clientes", ofreciéndoles subvencionar los servicios urbanos a cambio de apoyo electoral. Por lo general se requiere de la comunidad que recibe los servicios, que contribuya al proyecto con mano de obra y con dinero. También las compañias privadas se benefician con este tipo de proyectos de obras públicas. Con este sistema 
de "trueque" político es posible que todo el mundo gane.

De ahí que no resulte sorprendente el que un sistema de manejo comunitario como el SIRDO, pueda ser considerado inicialmente como un reto para aquéllos que tienen intereses en los sistemas ya establecidos de hacer las cosas. Los líderes comunitarios que tienen conexiones estrechas con los benefactores temen ver debilitada su posición con tales iniciativas vecinales. Es posible que algunos funcionarios del gobierno opongan resistencia, pensando que tales proyectos hacen a la población urbana menos dependiente del apoyo oficial, incrementando así su independencia política. $Y$ las empresas privadas temen perder la ganancia que les producen los grandes contratos de obras públicas. A la resistencia potencial de los interesados en conservar el status quo, se añade el escepticismo natural que inspira toda nueva tecnología, cuyos beneficios ambientales solo pueden demostrarse mediante un programa educativo.

Existe, sin embargo, creciente apoyo entre ciertos funcionarios del gobierno por sistemas de prestación de servicios y de tecnologías nuevos, como el SIRDO, porque estimulan actividades comunitarias de mutua ayuda y son menos costosos que los sistemas tradicionales. Esta actitud ha ganado fuerza en México, un país donde el gobierno se ve cada día menos capacitado para hacer inversiones tan costosas como las requeridas por la instalación de servicios convencionales de eliminación de desechos. Además, el SIRDO ha despertado gran interés por el papel que desempeña en reducir los riesgos de la contaminación ambiental y en instruir a la población urbana sobre la naturaleza de dicho problema. Fue por esto que, a pesar de los incidentes e impedimentos que se presentaron, el experimento pudo realizarse.

En octubre de 1981, para sorpresa de los residentes de la manzana experimental, la primera "cosecha" produjo casi una tonelada de fertilizante. Los miembros de la comunidad tuvieron que organizar el trabajo que requería sacarlo de la cámara y prepararlo para su propio uso o para la venta. No solo aumentó la cantidad de trabajo que se debía hacer, sino que fue necesario dar un mayor grado de organización a la comunidad. De ahí surgió la idea de crear una cooperativa. Después de solicitar información y asesoría técnica de varias fuentes, los residentes seleccionaron por votación el nombre de la cooperativa. La Ilamaron Muchuc-Baex, una expresión maya que significa "Unámonos". Al fertilizante le dieron el nombre de Tierra Bonita. En enero de 1982, la Cooperativa MuchucBaex, estaba legalmente constituída. De sus 18 miembros, 14 eran mujeres.

Doña Lucero, que anda cerca de los 30 años, pertenece a una familia de clase media. Estudió contabilidad y tiene un empleo de tiempo completo. Se expresa bien y sabe escribir en máquina (el único miembro de la cooperativa que puede hacerlo). Tiene dos niños. Su marido es carpintero. Por su gran habilidad como lider del grupo y su indeclinable interés en el SIRDO y en la cooperativa, doña Lucero ha sido su presidenta desde un principio.

La primera actividad económica de la cooperativa fue la venta del fertilizante. La operación requirió un capital pequeño para la compra de bolsas plásticas, etiquetas, una maquinilla de grapas, una balanza y unas pocas herramientas esenciales. El

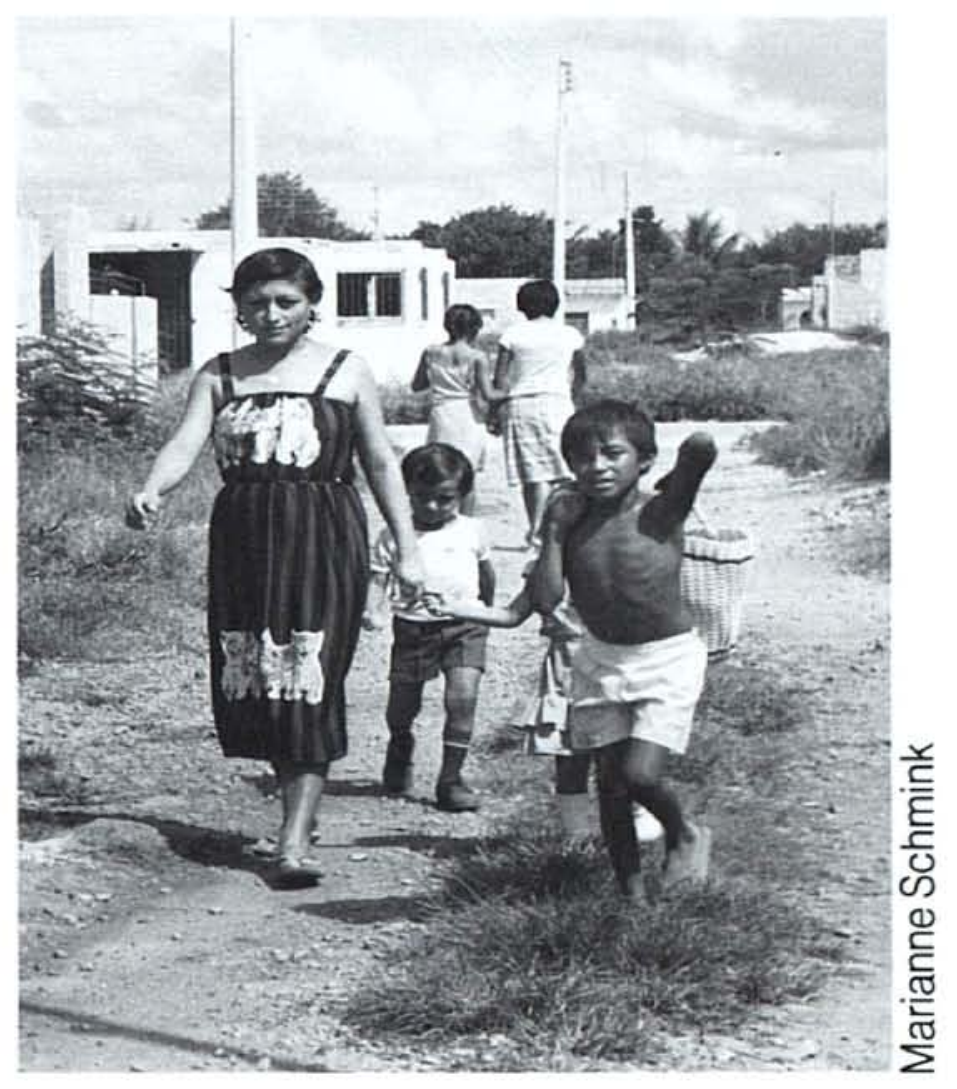


GTA le otorgó a la cooperativa varios préstamos pequeños durante este período inicial; ésta se los pagó más tarde con fertilizante.

Los miembros de la cooperativa extrajeron el fertilizante de la cámara, lo mezclaron con tierra, y lo empacaron en bolsas de un kilo de peso para venderlo. En un principio, las burlas de los vecinos ("Mujeres locas jugando con excrementos"), descorazonaron a algunas, y no participaron en estas tareas. Otras, sin embargo, perseveraron, y a fines de 1982, la cooperativa vendía su fertilizante en dos supermercados de la ciudad, produciendo una ganancia pequen̄a, pero muy simbólica para el grupo.

Ya en septiembre de 1983, GTA habia delegado en la comunidad casi toda la responsabilidad del mantenimiento del sistema, los nin̄os del vecindario habian escrito y llevado a escena su propia obra sobre la historia de la cooperativa, i.y Muchuc-Baex había recogido cuatro cosechas de fertilizantes! La calidad de éste se comprobó en los huertos de los miembros, y por medio de pruebas realizadas por la dependencia local del Ministerio Federal de Agricultura (SARH). Como medio de promoción, el grupo utilizó fotografías de don̄a Lola con un cohombro gigante que habia producido en su huerto.

Doña Lola es la única persona del grupo para quien el maya es el idioma nativo. Viene de un sitio donde se cultiva el henequén, en las afueras de Mérida. Cuando su primer esposo la abandonó, ella se trasladó a Mérida con don Alvaro, su segundo marido, que habia sido un dirigente campesino en su lugar de origen. Ahora trabaja para la ciudad como recolector de basura. Ambos se interesaron en el SIRDO desde el principio y asistieron a las reuniones del GTA antes de mudarse a la manzana experimental. Por la clase de trabajo que hacia, don Alvaro estaba interesado en el manejo de los desechos. Doña Lola, que siempre habia cultivado en su propio huerto los vegetales para la familia, vio el SIRDO como un medio de mejorar su producción de comestibles y de desempeñar un papel importante, haciendo experimentos con el fertilizante en sus sementeras. El cohombro gigante es

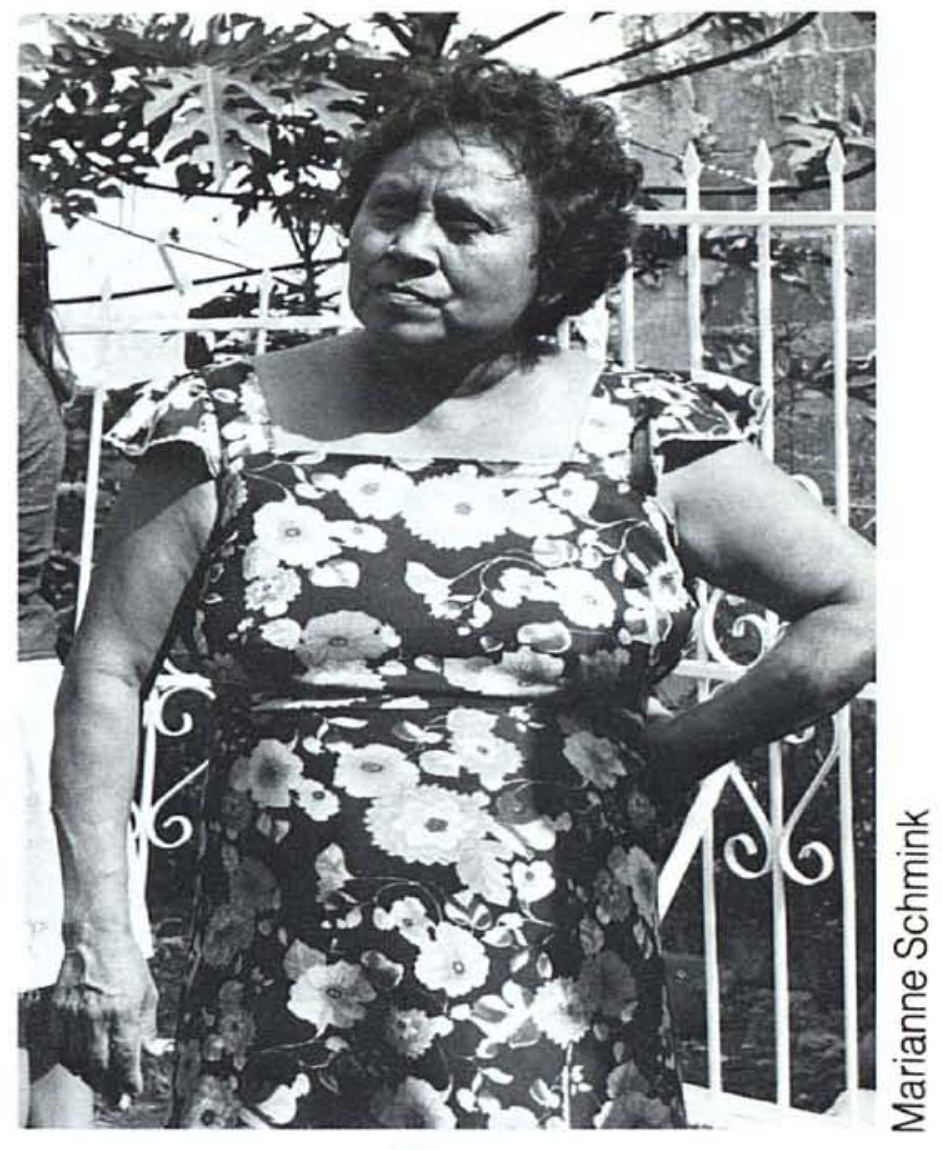

apenas una muestra del éxito que ha obtenido.

Con la asesoria técnica del GTA, ocho socios de la cooperativa se encargan del funcionamiento y mantenimiento del SIRDO. Por lo general, los hombres realizan las tareas más pesadas de limpieza periódica, recibiendo por ello un pago nominal. Los trabajos asociados con el funcionamiento diario del sistema, que no requieren mucho tiempo, lo realizan la mayoria de las mujeres de la comunidad que no trabajan fuera del hogar. Las tareas de mantenimiento las hacen por rotación los miembros del grupo, en forma voluntaria. Los requerimientos técnicos del SIRDO se describen en el "Manual del Biotero" que suministra el GTA y que sirve de guía de referencia para los gerentes comunitarios.

Aun estando convencidos de las ventajas del SIRDO, los integrantes de la cooperativa reconocen que existen algunos problemas. Sus casas no se diseñaron para este sistema y la tubería y los sitios de tratamiento de los desechos ocupan mucho del poco espacio disponible. Tampoco hay campo para tareas de mantenimiento tales 
como la limmpieza de los filtros. Además, se podrían introducir otras mejoras. Por ejemplo, las tapas de cemento de los filtros de aguas grises son tan pesadas, que por lo general las mujeres tienen que depender de los hombres para que las levanten. $Y$ se necesita equipo, como guantes y máscaras para proteger a los trabajadores del polvo fino que se levanta durante las operaciones de cernido y mezcla del material.

\section{El Fertilizante}

Para asegurar su factibilidad económica, la cooperativa necesita actualmente ampliar el mercado del fertilizante. Hasta el momento, han producido cuatro cosechas de una tonelada aproximadamente cada una, lo que representa apenas cerca de la mitad de la capacidad de las dos instalaciones. Las ganancias obtenidas se han reinvertido en la producción, (e.j. compra de tierra para la mezcla), dejando pequeñas sumas para distribuir entre los miembros. de acuerdo con el trabajo que realizan. Esperan mejorar su empresa en el futuro. adquiriendo una máquina mezcladora y construyendo una bodega de almacenaje.

En la etapa inicial en que se encuentra, la cooperativa ha accedido a vender el fertilizante por un precio inferior a su costo,

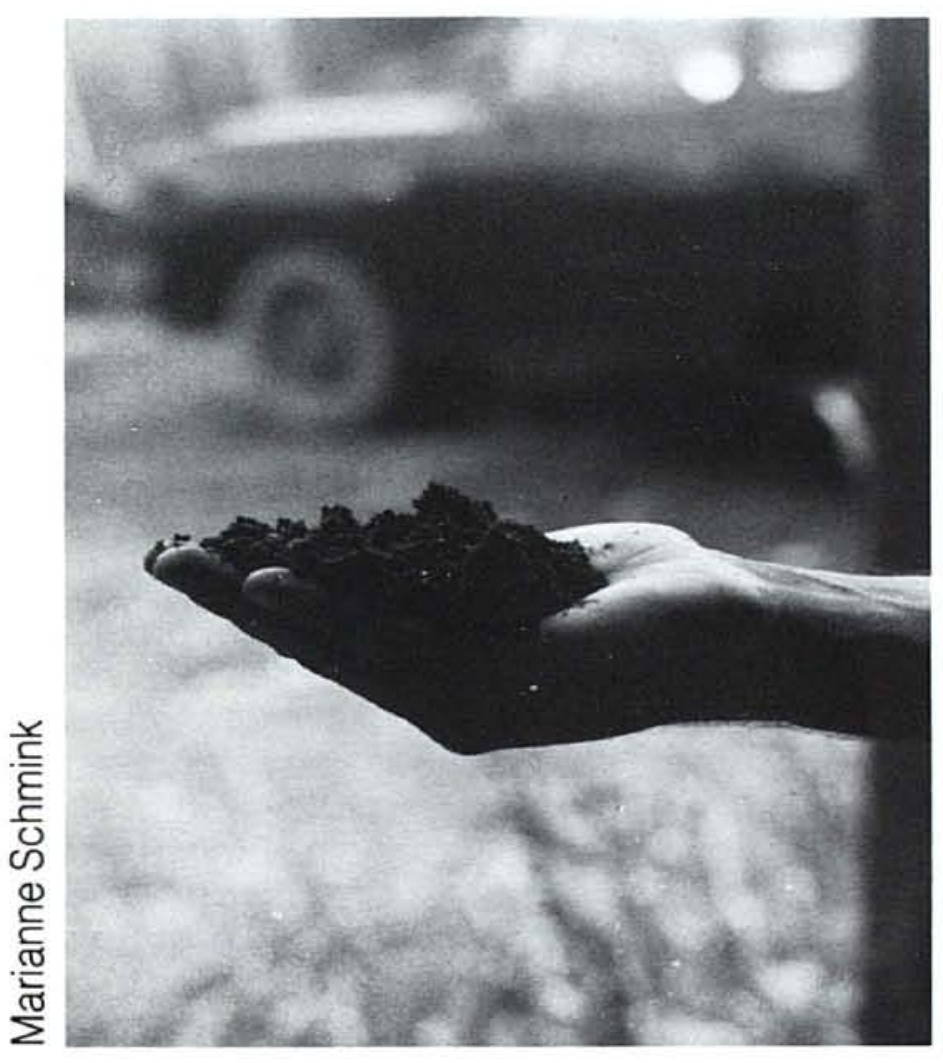

a fin de obtener un buen mercado. Los resultados favorables obtenidos en sus propios huertos les dan a los socios confianza en su producto y, además, la paciencia necesaria para esperar el día en que aumente la demanda. En la actualidad se lo venden principalmente a familias urbanas de clase media que lo usan en su jardín. Pero los miembros de la cooperativa confían en que más tarde podrán ponerlo en manos de los agricultores para mejorar la calidad de suelos agotados por demasiado uso, a cambio de los alimentos que necesitan sus familias. Hasta el momento, sin embargo, no han encontrado aún la forma de ponerse en contacto directo con los agricultores de la región.

\section{Nuevas Perspectivas}

Aparte del potencial económico que para los socios representa la venta del fertilizante, las actividades de la cooperativa tienen además un gran significado para la comunidad. Desde un principio ha estado constituída casi exclusivamente por mujeres, si bien es cierto que algunos maridos las ayudan regularmente con determinadas tareas. En otros casos, sin embargo, los hombres han tratado de impedir la participación de sus esposas, pero ellas, reconociendo el valor de las actuaciones colectivas, continúan participando en la organización.

Doña Betty, su marido don Tito y sus hijos, desempeñan un papel activo en la cooperativa. Ella es analfabeta y tiene diez nin̄os; nunca ha tenido un empleo de tiempo completo. El es panadero. Llegaron a la manzana experimental en noviembre de 1981, y comenzaron a interesarse por el SIRDO, cuando presenciaron por casualidad un acto de sabotaje contra él. Las personas que habian cerrado las válvulas los amenazaron más tarde con golpearlos si revelaban su identidad. El incidente pasó, pero la pareja comenzó a participar más directamente en la cooperativa. Por algún tiempo, don Tito, temeroso por su mujer, le prohibió que asistiera a las reuniones que ésta celebraba. Poco después de obtenerse la primera cosecha de fertilizante, tuvieron una pelea sobre el asunto. Doña Betty decidió resistir las órdenes del marido. A pesar de haber permitido que 
éste le prohibiera participar en otras actividades en el pasado, se dio cuenta de que era importante para ella tomar parte en la cooperativa. "No puedes", le dijo, "quitarme esto porque me está ayudando en mi desarrollo personal". Ahora cuatro miembros de esta familia toman parte en ella.

Para mujeres como éstas, el SIRDO sirve de base a una solidaridad comunitaria que sobrepasa en importancia los ingresos futuros que esperan recibir. Don̄a Lucero, la Presidenta de la cooperativa, dice al respecto:

La mayoría de los integrantes de la cooperativa no piensan en el dinero. Antes, viví por once años en otro sitio, sin saber los nombres de mis vecinas. Cuando me pasé aquí, viví otros tres años sin conocerlas. Sin saber su nombre, en caso de una emergencia a media noche, no hubiera podido llamar a mi vecina; tampoco ella a mí. Esta es la principal ventaja de la cooperativa. Ahora somos más hermanas que vecinas. Si no tengo dinero para comer, no me da verguenza pedirle a doña Candita que me preste doscientos pesos o que me dé las tortillas que le sobraron (arepas de maíz, base de la dieta mexicana). Eso es lo que ha hecho el SIRDO. Si no existiera, le aseguro que habría vivido

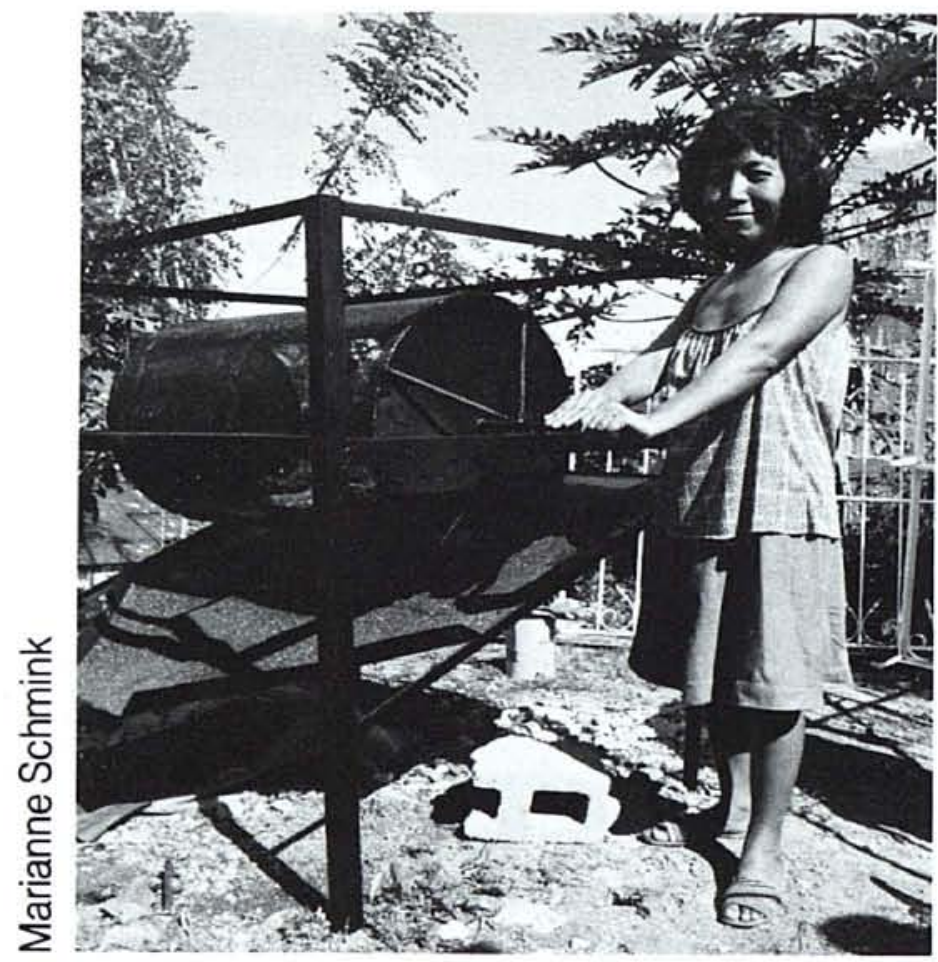

aquí todos estos años sin saber los nombres de mis vecinos.

Las mujeres de la comunidad aseguran que la ayuda mutua se extiende virtualmente a todos los aspectos de su diario vivir. Las integrantes de la cooperativa trabajan también juntas en otras actividades colectivas, entre ellas, la recolección de basura inorgánica para revenderla, y la compra al por mayor de vegetales, directamente de los agricultores. En 1981, construyeron un parquecito para sus niños y convencieron a las autoridades del estado para que donara el equipo necesario.

Doña Candita nació en la isla de Conzumel, cercana a la península de Yucatán. Cuando su primer marido la abandonó, vivió con su madre por un tiempo. Pocos años después el esposo regresó y le propuso que se fueran a vivir juntos a Mérida. Una vez alli, sin embargo, él continuó bebiendo en exceso y golpeándola de vez en cuando. Al final ella decidió separarse. Comenzó a preparar tamales, antojitos, empanadas y otros comestibles para venderlos en las cafeterias de la ciudad. Los hacía por la mañana en su casa y en la tarde salía a entregárselos a sus clientes. De esta manera consiguió sostener a sus cinco hijos; todos lograron terminar sus estudios. Doña Candita puede leer y escribir, pero con dificultad.

Se volvió a casar más tarde, pero otra vez encontró los mismos problemas con el segundo marido. Finalmente le dijo que no quería vivir más con él. Cuando se mudó a la manzana experimental, lo hizo sola. Fue el comienzo de una vida nueva y más independiente para ella. Al principio no participó en el SIRDO. Pero viendo cómo tomaba forma la cooperativa, quedó muy impresionada con lo mucho que trabajaban las otras mujeres y el personal del GTA. Ingresó a ella con gran entusiasmo, y fue elegida tesorera. En esta posición, ha sido partícipe de nuevas experiencias que han ampliado la confianza que tiene en si misma y la eficiencia de su trabajo en la cooperativa.

En febrero de 1982, el GTA intervino para que la invitaran a otro estado, a una reunión de funcionarios de la vivienda que estaban interesados en el SIRDO. Dos años más tarde asistió a otra reunión que sobre la 


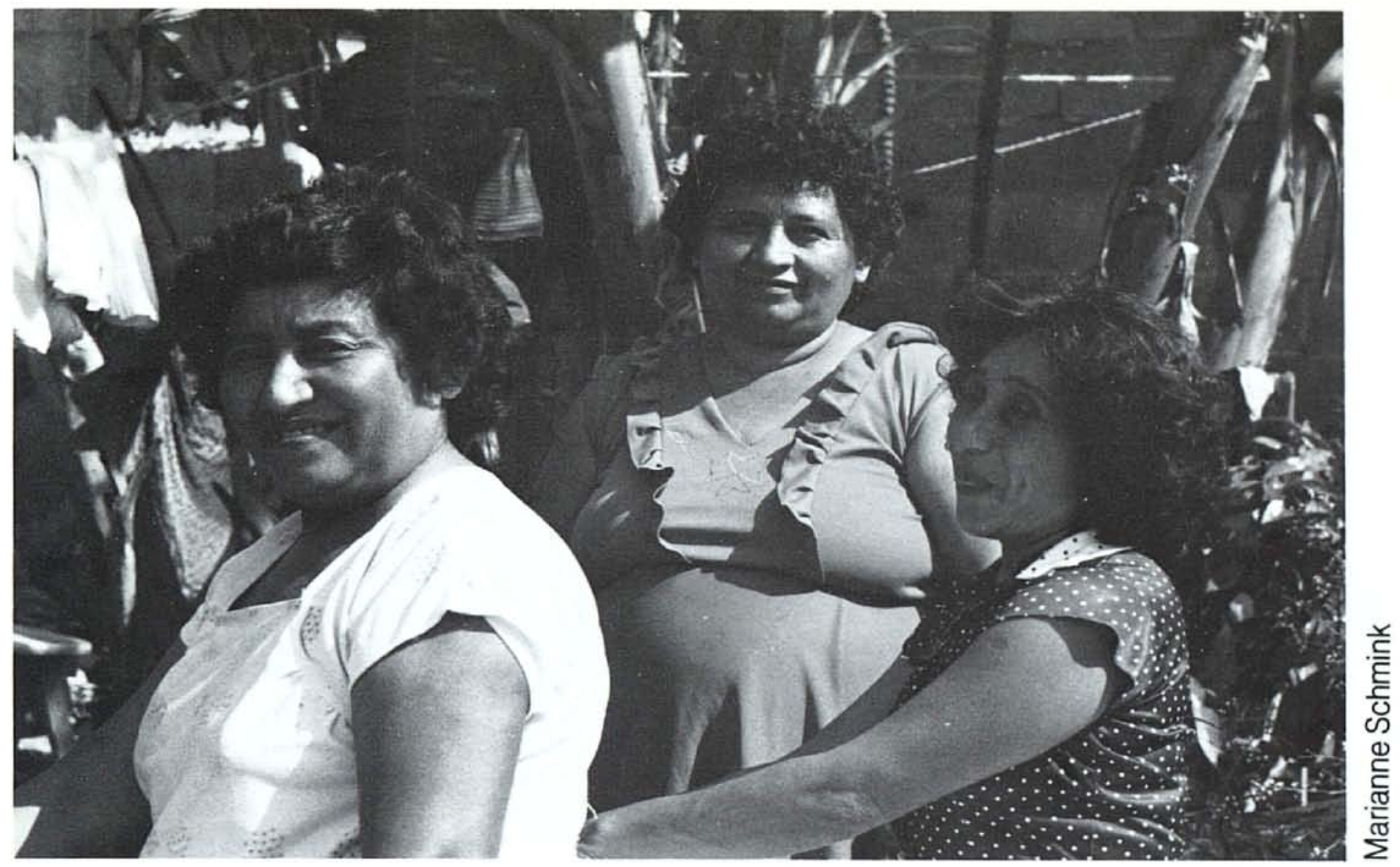

vivienda y a nivel nacional, patrocinaban el gobierno federal y los gobiernos estatales, en ciudad de México. Tuvo oportunidad entonces de describir ante los presentes las experiencias que su cooperativa habia tenido con el SIRDO. Durante cinco dias ella fue la única representante comunitaria en dicha conferencia. Esta experiencia la hizo más consciente de lo importante que era la labor de la cooperativa. Regresó a Mérida decidida a convencer a las autoridades locales y a los demás socios de la necesidad de cumplir el compromiso adquirido con el SIRDO. Continúa desempeñando un papel muy activo e influyente en las decisiones de la organización.

Doña Candita, que ya pasa de los 40 años, es el miembro de más edad de la cooperativa, a la que también ingresó su hijo Miguel. El interés de éste se deriva de los estudios que hace de ingeniería. En vista de los conocimientos que tiene, la cooperativa lo encargó de supervigilar el funcionamiento y mantenimiento del sistema.

\section{Segundo Sitio: el Valle de México}

El segundo proyecto experimental del SIRDO, en una comunidad urbana del Valle de México, ha aprovechado las lecciones aprendidas en Mérida. En 1978, en esta zona, que incluye la ciudad de México y sus alrededores, vivian unos 13 millones de personas, aproximadamente el 20 por ciento del total de la población mexicana. Aunque el crecimiento demográfico de la zona continúa aumentando a una tasa anual de un cinco por ciento más a menos, jel volumen de la basura que esta población produce ha subido a la pasmosa tasa del 30 por ciento anual! En 1984, la ciudad de México producía diariamente unas 13.000 toneladas de basura, de la cual aproximadamente una tercera parte eran materias orgánicas. En promedio, cada residente de la ciudad produce kilo y medio de desechos por día. Se calcula que entre el 70 y el 80 por ciento de estos desechos no se reciclan sistemáticamente, contribuyendo así a la contaminación del medio ambiente. Por otro lado, cerca de 10.000 personas traba- 
jan por cuenta propia en los muladares y calles de la ciudad, separando la basura y demás desechos, de acuerdo con el precio a que se los paguen. En promedio, los venden por el equivalente de US\$1 por kilo, a intermediarios que, a su turno, los revenden a la industria por tres o cuatro dólares el kilo. (US\$1 equivale aproximadamente a 167 pesos). Por consiguiente. sistemas alternativos de eliminación de desechos como el SIRDO, parecen ser muy apropiados para ambientes como éste.

La historia de esta comunidad donde el segundo SIRDO se instaló, es distinta de la de Mérida. Está situada cerca del extremo norte de la ciudad y la administra una cooperativa fundada en 1956, con unas 1.800 familias de bajos ingresos. Su primera actividad fue negociar la compra de terrenos para viviendas. Procedió enseguida a dividirlos en lotes, abrir calles y ayudar a los residentes a construir sus casas. Supervisó luego la instalación de energía eléctrica, de un sistema de suministro de agua de propiedad de la comunidad, así como la construcción de escuelas, zonas verdes y otros proyectos. Gracias a ello, el sitio se convirtió en un vecindario comparativamente más deseable que otros sectores menos organizados del valle de México.

En 1976 el problema de la eliminación de desechos comenzó a hacerse sentir. Los 18.000 habitantes de la comunidad, producian aproximadamente 240 toneladas de desechos por mes. Más o menos una tercera parte se recolectaba en camiones; el resto lo depositaban los residentes en cañadas, zonas verdes o lotes desocupados. También las zanjas destapadas de desagües iban a dar a las cañadas. En vista de la contaminación producida por estos depósitos, la comunidad comenzó a investigar maneras de solucionar tan creciente problema.

La primera opción que consideró fue un sistema convencional de desagüe de aguas residuales, cuyo costo en 1972, se calculó en 26 millones de pesos (un millón de dólares aproximadamente). Todo lo que la comunidad pudo reunir en los ocho años siguientes, fue un dos por ciento de dicha cantidad. En 1979, según otro estudio hecho por la municipalidad, el costo sería de 44 millones de pesos, sin incluir los costos directos que elevarían el valor del sistema a casi 60 millones de pesos (más de dos millones de dólares). Para esa época la cooperativa había logrado reunir dos y medio millones de pesos, alrededor del cuatro por ciento del costo total. Ante la imposibilidad de financiar el sistema convencional, la cooperativa comenzó a buscar soluciones alternativas. Fue entonces cuando se puso en contacto con el GTA de Mérida.

A principios de 1982, cuarenta miembros de la cooperativa del Valle de México viajaron a Mérida para asistir a una reunión de la Muchuc-Baex, y familiarizarse con el SIRDO. Poco después de su regreso, la asamblea general de su cooperativa decidió por mayoria de votos utilizar el dinero recolectado para el sistema convencional de desagüe, en la instalación de un SIRDO experimental, con la asesoría del GTA y de otros grupos de ciudad de México. Se estudió la financiación de las distintas etapas del proyecto. El sistema experimental prestaría servicio a 84 familias que ocupaban 40 lotes situados alrededor de un estanque natural, y a una escuela secundaria que tenía alrededor de 80 alumnos. Los planes incluian además experimentos de piscicultura en el estanque.

\section{Introducción del SIRDO: Avances y Conflictos}

Originalmente, solo un veinte por ciento de la población aprobaba la nueva tecnología; la mitad dudada de ella o no la entendía. El resto de la gente estaba en contra. A pesar de ello, los trabajos de construcción se adelantaron por 27 semanas y el sistema experimental se inauguró en diciembre de 1982 . Veintidós miembros de la comunidad donaron su trabajo. Los costos directos de construcción ascendieron a dos millones y medio de pesos, (alrededor de 55.000 dólares). Con el objeto de ayudar a instruir a la comunidad sobre el nuevo sistema, la Cooperativa Muchuc-Baex de Mérida, preparó un curso de siete lecciones para usuarios, promotores y técnicos. Tanto adultos como niños asistieron a ellas.

Inmediatamente que el sistema experimental comenzó a funcionar, otros dos sectores de la comunidad pidieron que se les considerara para el próximo SIRDO. 

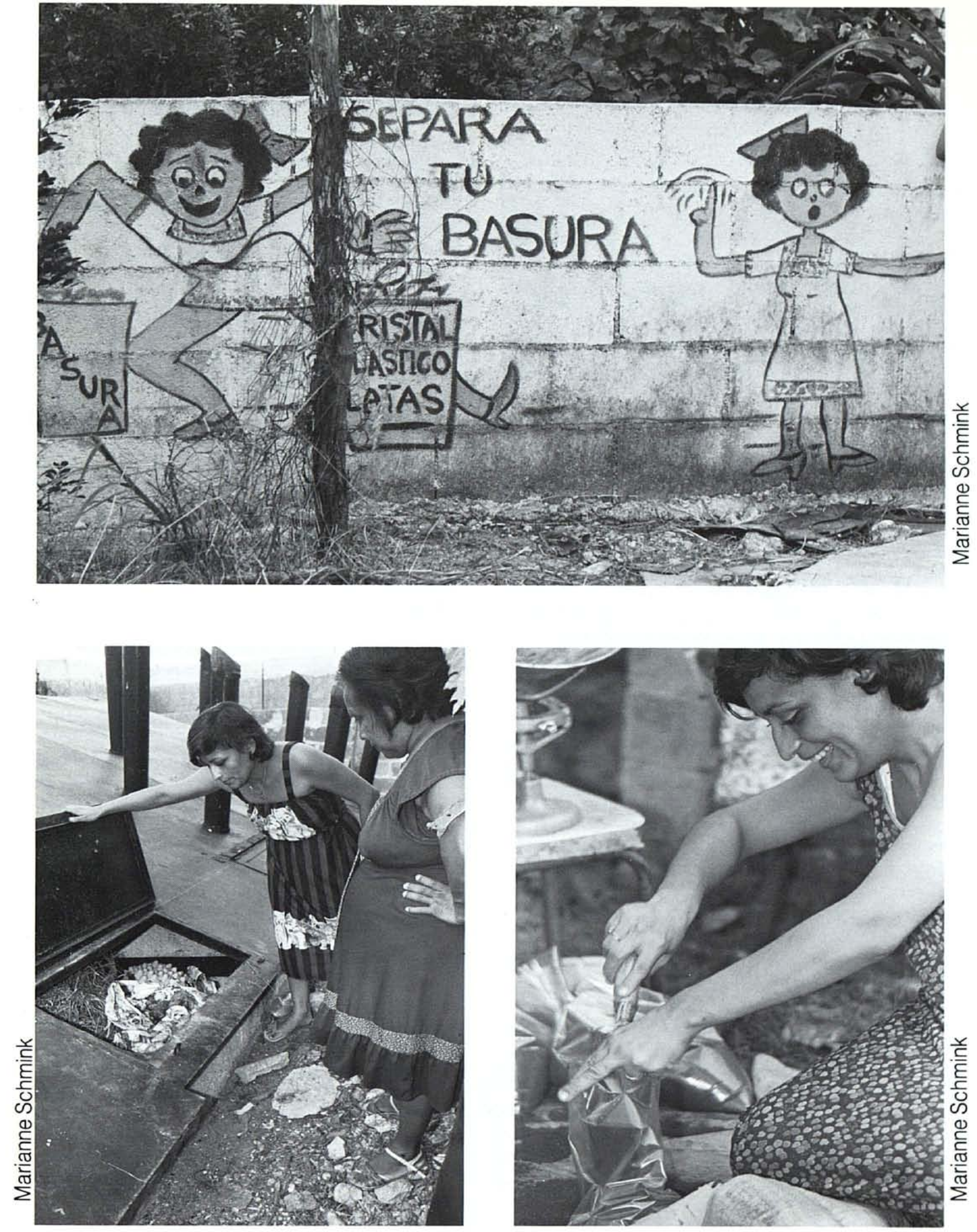
Uno de estos grupos formó un comité de 24 personas y nombró un tesorero en cada manzana para recolectar fondos destinados al proyecto. El GTA comenzó a preparar los diseños para estos dos sectores. Un Consejo Técnico integrado por representantes de la cooperativa, asesores técnicos y funcionarios de los gobiernos estatal y municipal, se formó para supervigilar las nuevas instalaciones.

Sin embargo, mientras los planes se ponían en marcha, los opositores del sistema también se organizaban. Formaron el Consejo de Colaboración Municipal que tácitamente se oponía a la construcción de los nuevos SIRDOS. Colocando ciertas personas en el Municipio, lograron que éste retirara su oferta de ayudar a instalarlos, prometiendo en cambio construir un sistema convencional de desagüe, a un costo de 300 millones de pesos (cerca de tres millones de dólares). La situación comenzó a ponerse tensa. El director de la escuela primaria de la localidad le prohibió a dos maestros llevar a sus alumnos al sitio del SIRDO, para darles una lección práctica sobre el medio ambiental. Además las rejillas de las chimeneas de la cámara de descomposición se rompieron durante un acto de vandalismo. En 1983 los opositores del SIRDO lograron ganar el control de la junta directiva de la cooperativa, pero la opinión de la comunidad propiamente dicha continuó dividida al respecto.

Contrariamente a lo que ocurre en Mérida, en el Valle de México solo un 30 por ciento de los socios de la cooperativa son mujeres. Además, como los estatutos de ésta solo permiten la participación de un miembro por familia, es el varón quien generalmente la representa. Una mujer, cuyo marido estaba ausente, se quejó de que le habian prohibido reemplazarlo en una reunión de la cooperativa. En cambio, en la Muchuc-Baex de Mérida, la participación es individual, permitiéndole así a las mujeres ejercer más influencia en las decisiones colectivas. Explica una de ellas: "A veces yo pienso de una manera y mi marido de otra. Pero los dos votos cuentan". No obstante, a pesar de estar limitadas en su participación directa en la cooperativa, las mujeres del Valle de México han encontrado la manera de ejercer colectivamente su influencia en cuestiones relativas a servicios básicos comunitarios, como el SIRDO.

No pasó mucho tiempo antes de que la nueva junta directiva de la cooperativa sintiera la presión femenina cuando falló el servicio de agua de la comunidad. Por varias semanas las mujeres fueron las más afectadas con el deterioro de las condiciones sanitarias y con el acarreo de agua desde sitios distantes. Algunas de ellas, que ni siquiera se conocían, formaron un grupo para discutir el problema. Sistemáticamente fueron organizando a los vecinos del sector, hasta que lograron derrocar la junta directiva y convocar nuevas elecciones. Consiguieron además que se formara una comisión encargada de supervigilar la labor de la junta directiva de la cooperativa. Seis de los nueve miembros de dicha comisión son mujeres.

Una vez que se resolvió el problema del agua, la comisión se ocupó de otros asuntos comunitarios, entre ellos, pavimentación de calles, zonas verdes y sistemas de desagüe. Cuando los obreros del municipio comenzaron a taladrar las calles del vecindario para instalar el desagüe convencional prometido, las mujeres protestaron. Algunas se enfrentaron individualmente a las partidas de trabajadores diciéndoles: "¡Ustedes no van a hacer huecos frente a mi casa!" Las apoyaron muchas otras mujeres que amenazaron a los funcionarios: "Si la arrestan a ella, van a tener que llevarnos a todas nosotras". La construcción del sistema convencional de desagüe se suspendió. Las señoras procedieron entonces a ejercer presión para que se pavimentara un camino que facilitaría la construcción y funcionamiento del SIRDO.

En el año que siguió a su instalación, la principal ventaja del SIRDO fue la mejora de las condiciones ambientales: menos moscos y menos ratas, ya que la basura y las aguas negras no se acumulaban en la cañada detrás de los hogares. No obstante, como solo una pequeña porción de las casas del vecindario estaban conectadas al SIRDO, continuaban existiendo otras causas de contaminación.

Como había ocurrido en Mérida, la producción de la primera cosecha de fertilizante trajo consigo el incentivo necesario para una mayor participación por parte de los usuarios. Usando sus contactos con 


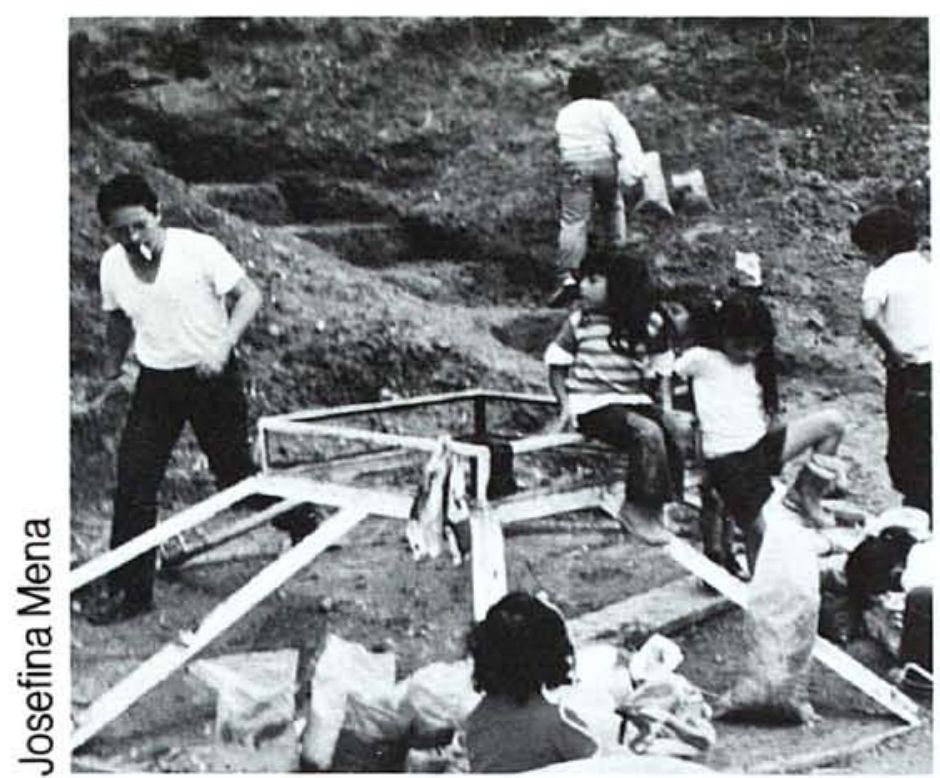

algunos asesores del gobernador del estado (que apoyaba el SIRDO), los residentes lograron que la dependencia estatal a cargo de los servicios de agua y saneamiento, examinara el fertilizante. Cuando se descubrió que todavía tenía algunas bacterias dañinas, los vecinos corrigieron el problema prolongando el secamiento y añadiendo mayor cantidad de materias orgánicas. En mayo de 1984 un segundo análisis dio mejores resultados.

En el entretanto, los usuarios del SIRDO comenzaron a organizar la labor de manufactura del fertilizante y a planificar otras actividades productivas. En marzo de 1984, unas 20 familias que utilizaban el sistema, formaron un grupo mejor organizado llamado "Grupo de Usuarios del SIRDO", que comenzó a sesionar una vez por semana. Uno de los residentes del vecindario, que es médico, procedió a instruir a ocho de los jóvenes del grupo sobre el mantenimiento del sistema y la recolección de basura. Como en este sitio existen mayor número de usuarios y mayores distancias entre las casas y la cámara de descomposición, esta división del trabajo se consideró más apropiada que el sistema comunal adoptado en Mérida. Los usuarios decidieron pagarle a estos jóvenes una suma pequeña, basada en el salario mínimo mexicano, por trabajar de dos a cuatro horas semanales. Para cubrir este gasto y los costos iniciales de otras actividades, los miembros convinieron en contribuir a los fondos del grupo con 500 pesos, (unos tres dólares) quincenales.

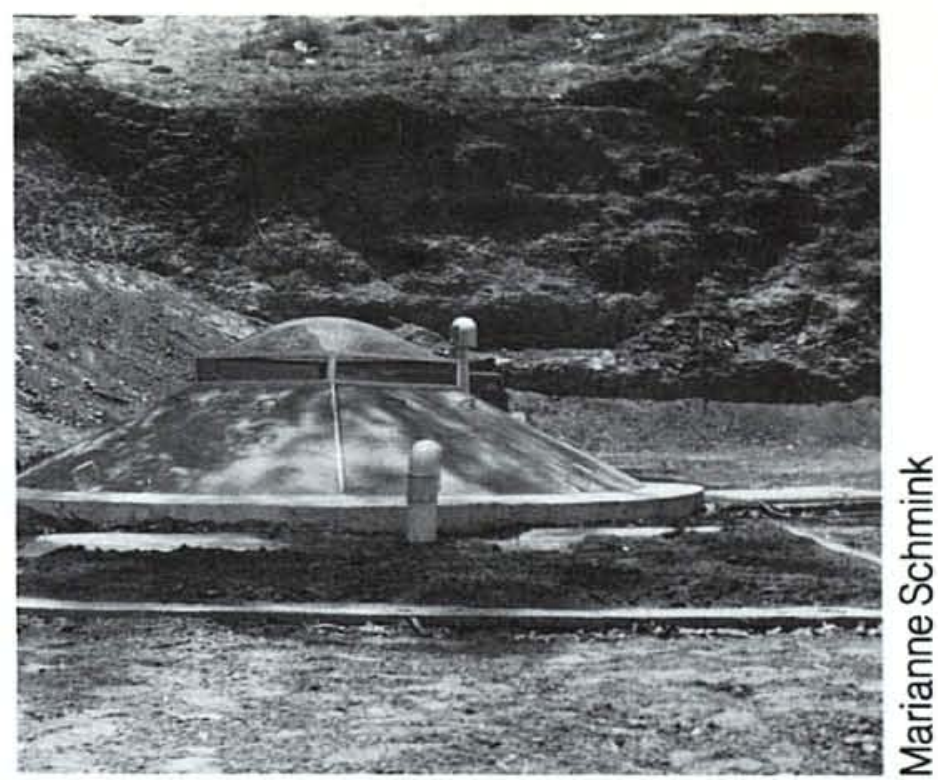

Poco después decidieron dar al grupo una mejor estructura, eligiendo funcionarios administrativos y creando seis comisiones especializadas. El director general y el secretario son hombres; la tesorera es mujer. También una mujer encabeza cada comisión. Se nombraron además asesores para asuntos técnicos, socialies y administrativos. Son profesionales que viven en el vecindario.

Cada comisión adoptó sus propias actividades. La Comisión I supervisa el funcionamiento y mantenimiento del SIRDO experimental, prestando atención especial a los aprendices jóvenes que lo tienen a su cuidado. La Comisión II prepara la producción y venta del fertilizante, al que se dio el nombre de ABOSIRD (Tierra Nueva). Pagaron alrededor de 50 centavos de dólar por el emblema bicolor que se imprimirá en las bolsas plásticas en que se empacará el fertilizante. Por el principio, la mayor parte de éste se distribuirá entre los usuarios del SIRDO; el resto se venderá para cubrir costos de producción. Ya otros residentes de la comunidad le han manifestado a la comisión su deseo de comprarlo también para abonar sus huertos. Se piensa además hacer un estudio del mercado, a fin de establecer un precio apropiado para el fertilizante.

Los objetivos que persiguen las otras cuatro comisiones son a largo plazo. Así lo expresa su lema: "Por una Comunidad Urbana Autosuficiente". La Comisión III se ocupa de planificar actividades productivas relativas al reciclado de materias plásticas, de metal y de vidrio. En el futuro 
espera ocuparse además del reciclado de la mayoría de los desechos orgánicos e inorgánicos del vecindario. Como primer paso, adelantó consultas con un especialista experto de la Universidad Nacional de México, que trata de perfeccionar una tecnología que permita convertir desechos plásticos en productos útiles, como tubería plástica de la que se usa en plomería y en la construcción de los SIRDOS.

La Comisión IV se dedica a desarrollar proyectos de horticultura. En pequeños lotes experimentales, cercanos a la cámara de descomposición, los miembros sembraron zanahorias, rábanos, calabazas, cebollas, tomates y hierbas. Dos biólogos voluntarios de la universidad local, los asesoraron y les dieron las semillas. La primera siembra no la abonaron con el fertilizante a fin de compararla más tarde con otras posteriores. También piensa la Comisión IV cultivar lotes en otras áreas aledañas al SIRDO. Cerca de éstos sembrarian árboles frutales, comenzando con aquéllos que como duraznos, peras y aguacates se dan bien en esa zona. Para regar estos cultivos, el grupo construye en la actualidad un tanque grande de reciclado de aguas grises procedentes del
SIRDO. Equipado con una bomba, producirá agua para riego todo el año. La meta final que se han fijado es llegar a tener 400.000 metros cuadrados de tierra produciendo regularmente alimentos para los 23.000 habitantes de la comunidad.

Con la ayuda de biólogos expertos, la Comisión $\mathrm{V}$ desarrolla planes para futuros proyectos de piscicultura que utilicen aguas negras ya tratadas, procedentes del SIRDO. Se construirian cuatro tanques para las diferentes etapas de purificación del agua; en el cuarto se criarían entre 6.000 y 10.000 truchas. Se calcula que la infraestructura y el adiestramiento de la comunidad requeridos para este proyecto, costarian aproximadamente unos 12.000 dólares, que deberian obtenerse de fuentes externas. Inicialmente el pescado se consumiría en la comunidad pero se espera que cuando aumente la producción, el excedente se pueda vender con alguna ganancia.

La Comisión VI tiene a su cargo la delicada tarea de supervisar el manejo de los desechos en las casas y proteger el medio ambiente. Son tareas primordialmente sociales y educativas. Los miembros de esta comisión examinan la composición

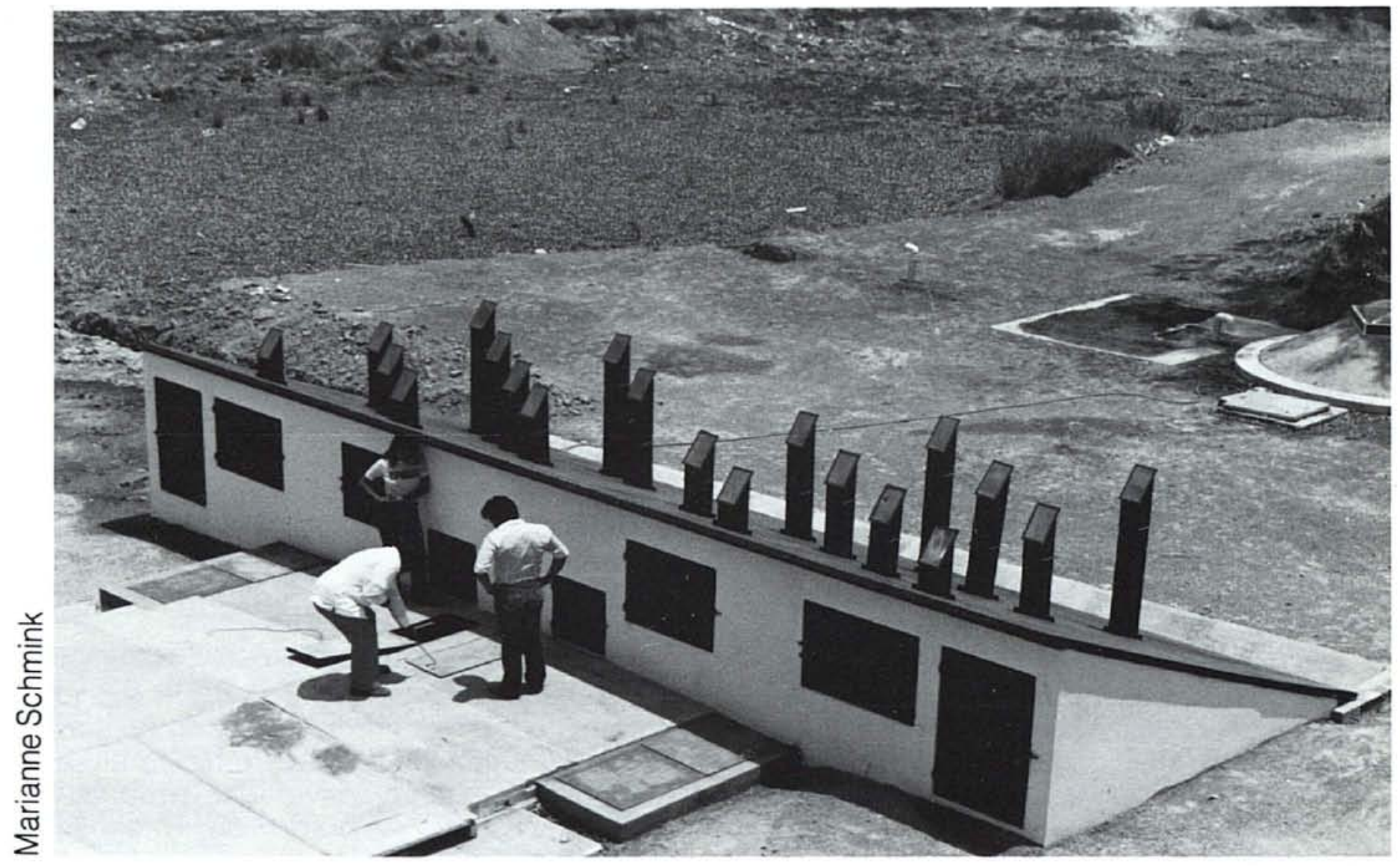




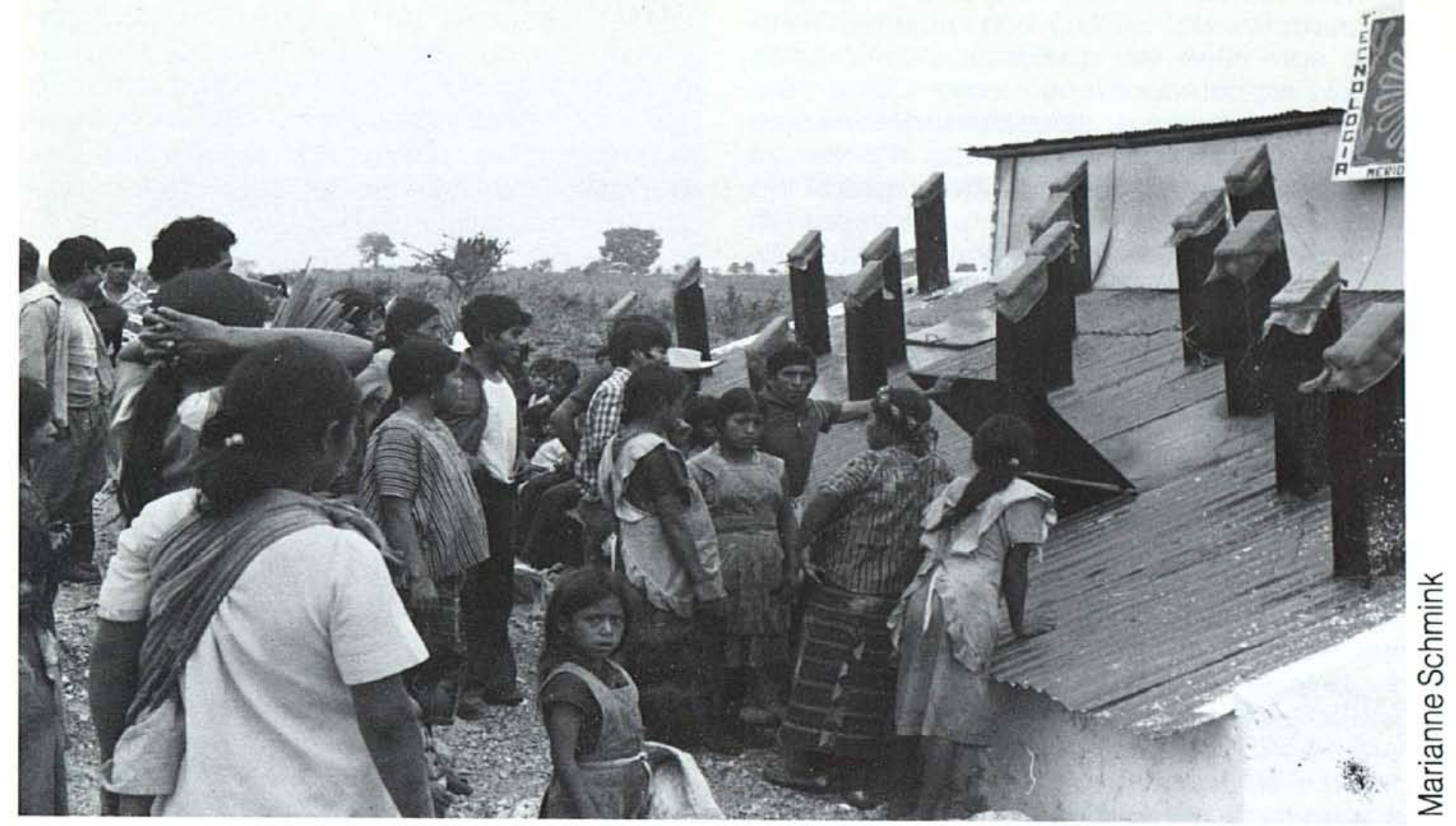

de la basura que se echa en la cámara de descomposición y hacen sugerencias para corregirla, si es el caso. Otras de sus tareas es ponerse en contacto con las 28 familias del sector cuyas casas todavía no están conectadas con el SIRDO. Tratarán de clarificar las ideas que dichas familias tienen sobre el sistema para que, o bien se decidan a utilizarlo, o renuncien a sus derechos, en forma de que otras familias de manzanas cercanas que sí están interesadas en usarlo, puedan hacerlo.

\section{Crecimiento y Cambio}

Todas estas actividades revelan un creciente reconocimiento de parte de los usuarios del SIRDO de la necesidad de establecer métodos eficaces de relaciones públicas dentro de la comunidad. También se han dado cuenta de que no deben ser agresivos en su oposición al sistema convencional de desagüe que prefieren algunas personas del vecindario. En vez de proclamarse sirdistas, le aconsejan ahora a esos vecinos que basen su decisión en un análisis de los méritos relativos de los dos sistemas. Confían en que la instalación del sistema convencional no se completará nunca por lo mucho que cuesta, y que el SIRDO, gradualmente, ganará adeptos entre los residentes del sector, a medida que las actividades productoras de ingresos comiencen a realizarse y que las condiciones ambientales se mejoren. Dentro de la comunidad hay ya 200 familias que desean que se instale el SIRDO en las manzanas en que viven.

Los usuarios del SIRDO hacen notar que el sistema ha contribuido a unificar más a los residentes de la manzana experimental y a mejorar las relaciones que existian entre ellos. La colaboración comunal diaria, asi como la labor de las comisiones y las reuniones semanales, han inspirado sentimientos de solidaridad. Tanto el SIRDO como las actividades relacionadas con él, han incrementado considerablemente la visibilidad de las mujeres en la colectividad y la confianza con que manejan los asuntos que a ellas conciernen. Si bien es cierto que los hombres continúan ocupando las posiciones directivas encargadas de tomar las decisiones que afectan a la comunidad, ellas han logrado aumentar su influencia mediante grupos de presión como el de la comisión 
que formaron cuando escaseó el agua. Más de la mitad de los integrantes de los grupos de usuarios del SIRDO son mujeres. También son ellas las que más involucradas están en el funcionamiento diario del sistema y las que encabezan todas las seis comisiones mencionadas antes. A pesar de no haber alcanzado todavía el grado de confianza e independencia logrado por las mujeres de Mérida, las del Valle de México, por su participación en el SIRDO, se están convirtiendo en una fuerza política.

\section{Potencial Económico}

El potencial económico del SIRDO depende de las actividades productivas que desarrollen los miembros de la comunidad. EI GTA calcula que se crearán de 50 a 80 empleos permanentes en el sitio del proyecto experimental del Valle de México, una vez que la producción del fertilizante, de la cría de peces y de los productos agrícolas esté establecida. Los costos del fertilizante se pueden reducir más de la mitad si se utiliza al máximo la mano de obra comunitaria. El proyecto de Mérida ha demostrado que un kilo de fertilizante que se vende por el equivalente de 70 u 80 centavos de dólar, se puede producir por menos de cinco centavos de dólar por kilo. Los materiales que entran en la producción de cuatro toneladas de fertilizante cuestan solo 250 dólares por año. La enorme demanda de fertilizantes de precio bajo en todo el mundo, incluyendo a México, es claramente un incentivo económico para incrementar al máximo la producción de este tipo de abono.

\section{Expansión}

Después de seis años de haberse instalado el primer proyecto experimental en Mérida, el SIRDO goza de gran visibilidad y credibilidad en sectores claves del gobierno, la prensa y el sector académico. A comienzos de junio de 1984, los tres principales periódicos de la nación adelantaron la "Operación SIRDO", una campaña de apoyo al sistema. Se lo presentó como la solución al problema de la contaminación ambiental que confrontan las ciudades mexicanas. Científicos de varias instituciones gubernamentales y académicas se interesaron en asuntos como reciclaje de plásticos, piscicultura, agricultura y el estudio de los usos potenciales del fertilizante, después de que el GTA los convenció de que debían aplicar sus conocimientos a la solución de los problemas de las comunidades pobres. El GTA logró además ganar aliados dentro de las esferas del gobierno, a fin de neutralizar a los opositores del SIRDO en otros sectores oficiales. En Mérida, por ejemplo, el nuevo gobernador del estado y los funcionarios federales de la vivienda, presionaron a las autoridades regionales que se oponían a él, con el resultado de que el gobierno estatal convino en compartir con la comunidad el costo de unas reparaciones que el sistema necesitaba.

En 1984, el GTA construía SIRDOS no solo para grupos comunitarios, sino para el gobierno y el sector privado. PEMEX, la compañía petrolera del Estado, piensa instalar diez SIRDOS por año en sus nuevos sitios de operaciones, a fin de impedir la contaminación ambiental. Las dependencias federales para desarrollo urbano y ecología, han comenzado a trabajar con el GTA en varias comunidades, y les gustaría construir tantos SIRDOS como sea posible en los próximos años. A los estudiantes universitarios se los prepara para que trabajen con las comunidades donde se instalen estos sistemas.

Con la creciente aceptación pública del SIRDO, el GTA afronta ahora problemas de otra clase. Los planes actuales incluyen la creación de cooperativas de trabajadores destinadas a producir algunos de los materiales que entran en la construcción del SIRDO. Con ello se daría trabajo a las personas de la comunidad que han participado en la instalación de los sistemas. Estos materiales se le venderian a los sectores públicos y privados.

\section{Cambios en la Prestación de Asesoría Técnica}

A medida que la responsabilidad de administrar y mantener los sistemas se pasa gradualmente a la comunidad, el papel de GTA es más y más el de un asesor técnico externo. Este proceso es parte de la meta que se ha trazado el GTA, de diseñar un sistema que altere las relaciones entre 


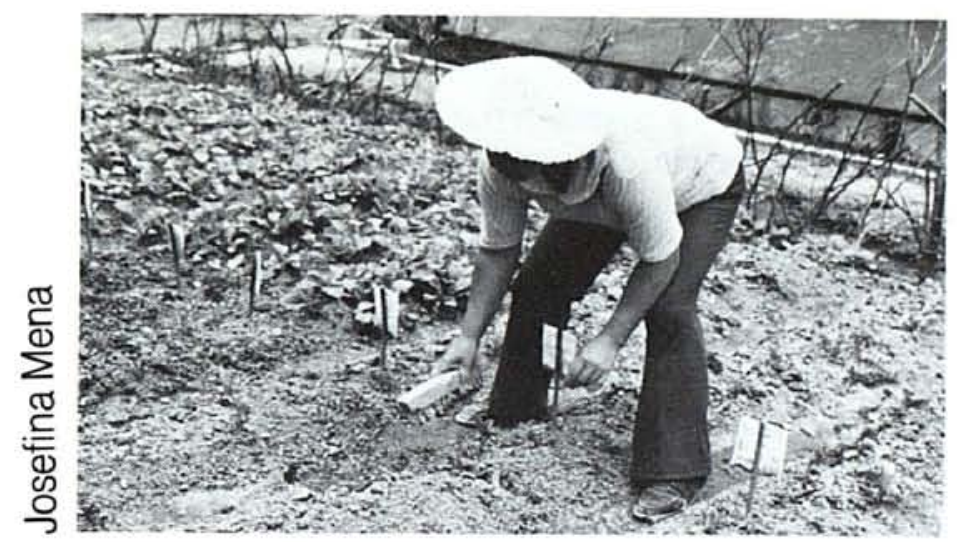

los usuarios, la tecnología y el medio ambiente, a fin de promover actuaciones colectivas como una alternativa a la dependencia pasiva en gobiernos que, frecuentemente, carecen de voluntad o de recursos para atender las demandas de la localidad. Tanto en Mérida como en el Valle de México, esta transferencia ha resultado en ciertas ocasiones en períodos de tensión, cuando los miembros de la comunidad comienzan a demostrar su independencia tomando decisiones contrarias a las recomendadas por el GTA. Después de estas experiencias, el GTA modificó la estrategia que empleaba en la transferencia de tecnología, a fin de reducir las posibilidades de errores técnicos. Ahora, antes de introducir el sistema, el GTA crea un Comité de Salud comunitario, y una Cooperativa de Producción TATA (Talleres Asociados de Tecnologías Alternativas). para que se encargue de todas las decisiones concernientes a las actividades productivas del sistema. Un número pequeño de miembros de la comunidad reciben el adiestramiento necesario para manejar y mantener el sistema dentro de las limitaciones técnicas establecidas por el GTA.

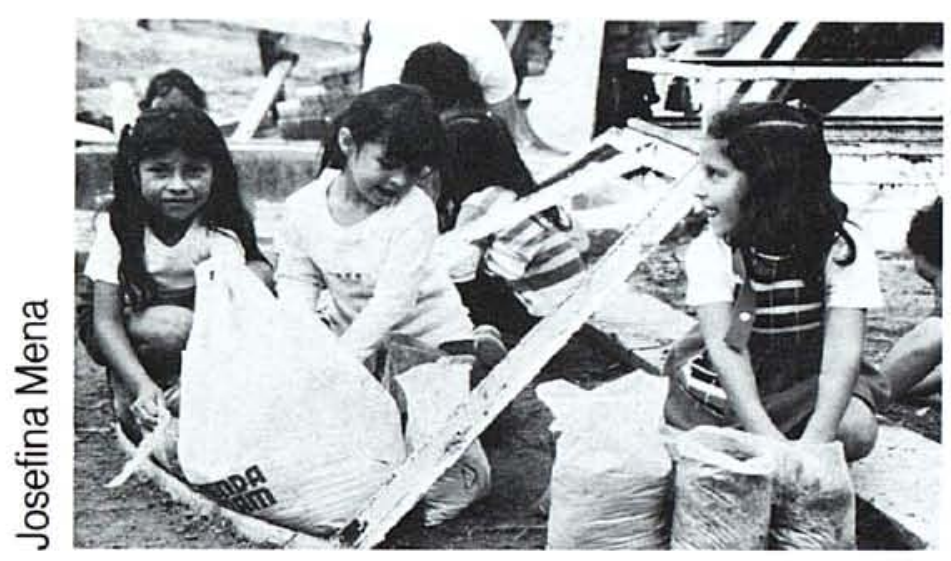

Los dos proyectos experimentales, en Mérida y en el Valle de México, ponen de presente algunos de los problemas y posibilidades inherentes a la introducción de nuevas tecnologías. La aceptación comunitaria de innovaciones como el SIRDO, requiere que se superen obstáculos técnicos, sociales y políticos. Por su participación en la eliminación de desechos domésticos y comunitarios, por la prioridad que le dan a un ambiente sano y por la necesidad que tienen de nuevas fuentes de ingresos, las mujeres desempeñan un papel muy importante en la promoción, comprensión y aceptación de tecnologías nuevas como el SIRDO. Por otra parte, su participación en tales actividades sirve de catálisis a su organización colectiva. Su efectividad contribuye a hacerlas más notorias y a que se tome en cuenta su opinión en los asuntos comunitarios. Por último, el potencial del sistema de producir ingresos con la venta del fertilizante, ( $y$, acaso, más adelante de frutas, vegetales y pescado), le ofrece además a las mujeres mayores oportunidades de independizarse económicamente. 


\section{Lecciones Aprendidas}

1. La introducción de una nueva tecnologia depende tanto de procesos técnicos como de procesos sociales. Requiere que los miembros de la comunidad adquieran una obligación a largo plazo. Los aspectos técnicos, aun los más complicados, pueden entenderse fácilmente si se usan métodos prácticos de adiestramiento. En el caso de la tecnología del SIRDO, las características ecológicas de cada lugar diferente, exigen la activa colaboración de los miembros de la comunidad para poder adaptarla al ambiente local. La planificación y organización de las actividades productivas asociadas con el sistema, son aún más complejas y requieren que la comunidad establezca prioridades, y analice las distintas tareas que van a competir por su tiempo y recursos. Por eso es tan importante que los técnicos sean realistas en su apreciación y comprensión del delicado proceso de la transferencia de tecnología.

2. El tipo de participación comunitaria asociada con la administración de los desechos, o de cualquier tecnología nueva, es un proceso que cambia con el tiempo. El aprendizaje de cómo manejar y mantener el sistema y de convencer a los escépticos de sus ventajas, se efectuaron durante el primer año. La primera cosecha de fertilizante, que impuso tareas adicionales a los miembros de la cooperativa, fue, además un incentivo tangible para obtener una mayor participación de su parte. El reconocimiento de estas diferentes fasetas del proceso, ayudará a las comunidades a prepararse para responsabilidades mayores asociadas con la administración del sistema; las ayudará además a tener más paciencia para superar el escepticismo que aún perdure.

3. Las mujeres y la comunidad deben ver beneficios inmediatos en la adopción de la nueva tecnología. El beneficio inmediato del SIRDO es la mejora del saneamiento físico que tanto les interesa. El potencial del sistema como actividad generadora de ingresos sobre una base comunitaria, no es una ventaja inmediata $y$, por ende, no se debe hacer hincapié en ella en un principio. En cambio, deben destacarse las ventajas ambientales y promoverse la mutua cooperación. La participación femenina en el manejo de los servicios esenciales para la comunidad puede acrecentar su influencia en los asuntos que a ésta conciernen y en sus relaciones con las autoridades de fuera de la colectividad. En Mérida, la necesidad de hacer funcionar y mantener el SIRDO, y de atender a la producción del fertilizante, resultó en la formación de una estructura cooperativa dominada por las mujeres, la que las imbuyó de fuertes sentimientos de solidaridad mutua, a pesar de no haberse conocido antes. De la misma manera, aumentó también su independencia y su confianza en sí mismas, en las relaciones que tienen con el marido y los demás miembros de la familia. En el Valle de México, una cooperativa estable, establecida con anterioridad, y dominada por los varones, inicialmente le negó a las mujeres acceso a las posiciones directivas encargadas de la toma de decisiones. A pesar de ello, el SIRDO estimuló la creación de organizaciones nuevas, menos formalizadas, en las que la influencia femenina en asuntos comunitarios se hace sentir más. Su convencimiento cada vez mayor de la eficacia de las actuaciones colectivas, se ha extendido a otros asuntos que, como el manejo de los servicios de agua, preocupan a la colectividad.

4. La estructura de la cooperativa amplia la habilidad de la población para afrontar otros problemas comunitarios y para tener de ellos una visión a largo plazo. El aprender a hacer decisiones técnicas colectivas refuerza la confianza y el sentido analítico de los socios. El uso de desechos reciclados aumenta la autosuficiencia de la comunidad y constituye un aprendizaje excelente sobre conservación de recursos y protección ambiental.

5. Las nuevas tecnologías se deben ir modificando a medida que los requerimientos de la participación femenina en su funcionamiento se clarifiquen. Como las mujeres y los jóvenes generalmente se encargan de la eliminación de los desechos y del saneamiento hogareños, y con menos frecuencia trabajan fuera de la casa, ellos son las personas más capacitadas para dedicar el tiempo que requieren la operación y mantenimiento del sistema. A su turno, dicho trabajo debe organizarse en 
forma de que ellos puedan realizarlo sin ayuda de fuera. (Por ejemplo: el peso de ciertos elementos del sistema original debe reducirse a fin de que las mujeres y los niños puedan moverlos). La participación infantil constituye una experiencia educativa única; no solo se instruyen los muchachos en cuestiones relativas a la protección ambiental, sino que se les puede enseñar a realizar tareas como las de hacer pruebas rutinarias del fertilizante en el laboratorio.

\section{La responsabilidad de adminis- trar el sistema debe transferírsele gradual- mente a la comunidad, pero suministrán- dole suficiente asistencia técnica externa}

para asegurar un mantenimiento apropiado. La introducción de una nueva tecnología requiere una fuerte infusión inicial de asesoria técnica externa, mientras los miembros de la comunidad se adiestran para encargarse de la operación. A medida que reciben mayores responsabilidades, dichas personas deben adquirir la confianza que necesitan para tomar decisiones independientes o, en ocasiones, contrarias al consejo de los mencionados expertos. Los errores que cometan son parte del proceso de aprender a evaluar y discutir las decisiones colectivamente. No obstante lo anterior, aún es necesaria la asesoría técnica externa, para solucionar los nuevos problemas técnicos que se presenten.

\section{APENDICE}

Partes de esta descripción se tomaron de Documentación y Evaluación de Experiencias Tradicionales y Alternativas para el Manejo de Residuos Urbanos en Zonas de Bajos Ingresos en el Valle de México, el informe sobre el proyecto redactado por Fernando Ortiz Monasterio, Josefina Mena y Angel Parada, en octubre de 1983. Fue escrito en la ciudad de México para el grupo de trabajo Mujer y Ciudad, parte de un proyecto conjunto del Population Council y la USAID sobre "Women, Low Income Households and Urban Services in Latin American and the Caribbean", del cual Marianne Schmink es cogerente. Para mayor información sobre el proyecto escriba a: Judith Bruce, The Population Council, One Dag Hammarskjold Plaza, New York, NY, 10017, USA.

Información sobre el SIRDO puede obtenerse de: Grupo de Tecnología Alternativa, Calle Almo 8-16 Col. Los Alamos, Jardines de San Mateo, Naucalpan, Edo. de México, 53230 México (Teléfono 393-7414).

Entre las demás fuentes de información de fondo sobre eliminación y reciclamiento de desechos, se cuentan las siguientes:

Appropriate Technology for Water Supply and Sanitation: Meeting the Needs of the Poor for Water Supply and Waste Disposal, by Frederick L. Golladay, Washington, D.C.: World Bank Technical Paper, 1983

Food, Fuel and Fertilizer from Organic Wastes. Report of an Ad Hoc Panel on the Advisory Committee on Technology Innovation, Board on Science and Technology for International Development, Commission on International Relations, National Research Council, Washington, D.C.: National Academy Press, 1981.

Low-Cost Technology Options for Sanitation. A State-of-the-Art Review and Annotated Bibliography, by Witold Rybcznyski, Chongrak Polprasert, and Michael McGarry. Ottawa, Canada: International Development Research Centre. 


\section{Algunas Organizaciónes Regionales para Asistencia Técnica}

\section{Africa}

Blair Research Laboratory

P.O. Box 8105

Causeway

Harare, Zimbabwe

Technology Consultancy Centre

University of Science and Technology

Kumasi

Ghana

Attention: Dr. J.W. Powell

Arusha Appropriate Technology Unit

P.O. Box 764

Arusha

Tanzania

\section{Asia and Pacific}

Action for Food Production (AFPRO)

C-17 Safdarjung Development,Area

New Delhi - 110016

India

Attention: Mr. Raymond Myles

Khadi and Village Industries Commission Gobar Gas Scheme

Irla Reas, Vile Parle

Bombay 400-056

India
Ministry for Agriculture

Division of Soil Science

Kathmandu

Nepal

Attention: Mr. Joshy

South Pacific Appropriate Technology

Foundation

P.O. Box 6937

Boroko

Papua New Guinea

\section{Latin America}

Pan American Centre for Human Ecology and Health

P.O. Box 249

Toluca

Mexico

Attention: Dr. Stephen W. Bennett

\section{International}

Tool

Mauritskade 61 a

1092 AD Amsterdam

Netherlands

International Reference Centre for Community Water Supply and Sanitation P.O. Box 93190 2509 AD The Hague Netherlands 
Diseño: Ann Leonard

Tipografia: Village Type \& Graphics

Foto de la Portada: Marianne Schmink

Impresor: Graphic Impressions, Inc.

Traducción: Myriam Luz

Invitamos a nuestros lectores a que nos envien sus comentarios, así como ideas para proyectos que puedan incluirse en futuras ediciones de SEEDS. Las personas que deseen recibir copias adicionales de este folleto o que su nombre se incluya en la lista de distribución de esta publicación, pueden dirigirse a:

Ann Leonard, Directora SEEDS

P.O. Box 3923

Grand Central Station

New York, New York 10163 U.S.A. 


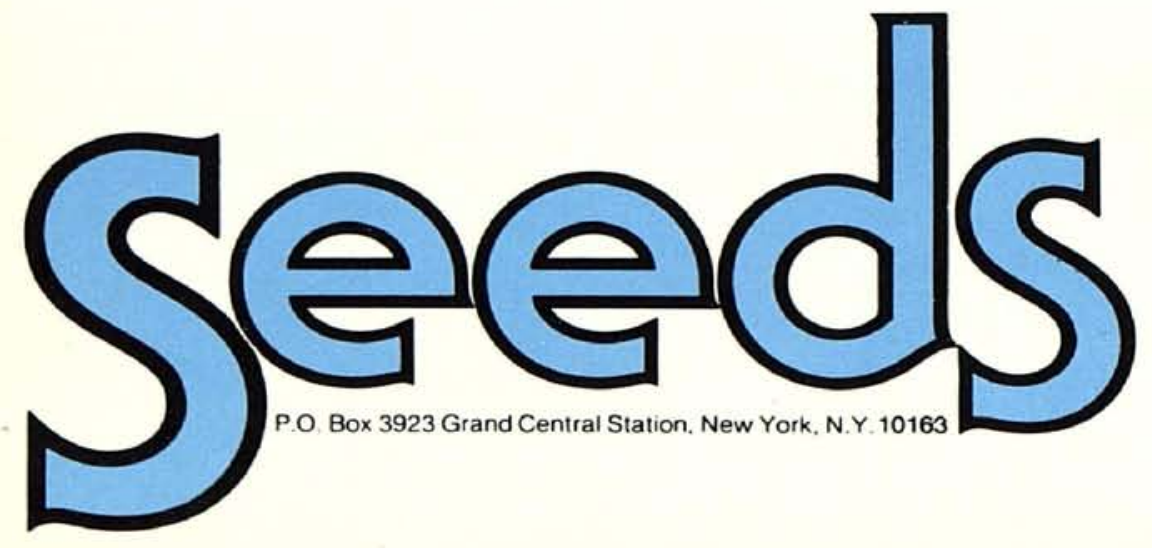

